\title{
Evaluation of an ESP Textbook for the Students of Sociology
}

\author{
Sasan Baleghizadeh \\ Department of English Language and Literature, Shahid Beheshti University, G.C., Tehran, Iran \\ Email: sasanbaleghizadeh@yahoo.com \\ Amir Hossein Rahimi \\ Department of English Language and Literature, Allameh Tabataba'i University, Tehran, Iran \\ Email: amh_faith@yahoo.com
}

\begin{abstract}
The present paper is an attempt to describe the process that was undertaken to evaluate the textbook English for the Students of Sociology: Social Science Texts taught at the University of Tehran. The purpose of this research project was to determine the overall pedagogical value and suitability of the book toward this specific language program. To achieve this goal, a questionnaire consisting of 20 items and examining 6 factors (practical concerns, materials in relation to course objective, subject matter, linguistic issues, skills and strategies, variety of tasks and activities, and the layout of materials) was used. Participants included 30 students of sociology, who were taking an ESP course at the University of Tehran. The findings indicated that the book, despite having merits, was not very suitable for the course. Suggestions regarding the kinds of activities, strategies, layout and other important issues are discussed.
\end{abstract}

Index Terms-ESP, English language teaching materials, textbook evaluation

\section{INTRODUCTION}

English for specific purposes (ESP) has been around for about 40 years. Dudley Evans and St John (1998) maintain that ESP is part of a more general movement of teaching language for specific purposes (LSP). ESP has attracted more attention within the teaching of English as a foreign or second language. Hutchinson and Waters (1987) argue that ESP must be seen as an approach not as a product. It does not consist of a particular type of teaching material, nor is it a particular kind of language or methodology. As the name suggests, ESP is designed for a particular group of people in a particular context. The materials used are related to the learners' specialized field of study. One of the important factors which is of utmost importance in language learning in general and ESP in particular is to see whether the books and materials are useful for the purpose of the course or not. This is done through the process of textbook evaluation, which is the aim of the current study.

\section{A. Materials and Books}

In every teaching context, textbooks play an important role in imparting learning and assisting teachers to fulfill their responsibility. According to Riazi (2003, p. 52), "textbooks play a very crucial role in the realm of language teaching and learning and are considered the next important factor in the second/foreign language classroom after the teacher."

Likewise, As Hutchinson and Torres (1994) put it:

The textbook is an almost universal element of [English language] teaching. Millions of copies are sold every year, and numerous aid projects have been set up to produce them in [various] countries... No teaching-learning situation, it seems, is complete until it has its relevant textbook. (p.315)

O'Neill (1982) presents four reasons for the use of coursebooks. Firstly, most parts of coursebook materials are appropriate for students' needs, even if they are not specially designed for them. Secondly, they make it possible for students to plan for future learning and also review the previous materials or lessons. Thirdly, coursebooks provide students with high quality materials at a reasonable price. Finally, suitable coursebooks allow teachers to adapt and modify them to meet the learners' needs and also allow for natural interaction to happen. Dudley-Evans and St John (1998) believe that books and materials play a crucial role in every learning situation and help teachers with their responsibilities. They provide four justifications for using materials and books: a) as a source of language, b) as a learning support, c) for motivation and stimulation, and d) for reference.

Hutchinson and Waters (1987) define six objectives for materials: they should (a) provide a stimulus for learning, (b) help to organize teaching and learning process, (c) embody a view of the nature of language and learning, (d) reflect the nature of the learning task, (e) have a very useful function in broadening the basis of teacher training, and (f) provide models of correct and appropriate language use. 
Although coursebooks play an important role in the learning process, it should be noted that a number of scholars argue that a heavy dependence on a book and not using complementary materials can have negative consequences on the students (Allwright, 1981; Cunningsworth, 1995; Stern, 1992; Swales, 1980).

\section{B. Evaluation}

Textbooks are among the most important resources utilized to achieve the aims of a course which are based on the learners' needs. However, they should not become the aim of the course themselves and set those aims (Brown, 1995). Regarding the importance of the textbooks, one should make sure that those books meet appropriate criteria. In Cunningsworth's (1995) words, we should ascertain that "careful selection is made, and that the materials selected closely reflect the aims, methods, and values of the teaching program" (p.7).

One of the methods which can help us in achieving the aforementioned goal is the evaluation process. As Nunan (1991) observes:

the selection process can be greatly facilitated by the use of systematic materials evaluation procedures which help ensure that materials are consistent with the needs and interests of the learners they are intended to serve, as well as being in harmony with institutional ideologies on the nature of language and learning. (p.209)

Sheldon (1988) has suggested several reasons for textbook evaluation. He states that the selection of a textbook is indicator of an educational decision in which there is considerable professional, financial, and even political investment. Through evaluation, teachers will become familiar with the content of available textbooks and recognize the weaknesses and strengths of each.

One more reason for evaluation is suggested by Cunningsworth (1995) and Ellis (1997). They argue that evaluation can be considered as a means of conducting action research as well as a form of professional empowerment and improvement. It can also be a component of teacher training courses in which prospective teachers become aware of important features which they should search in textbooks. Cunningsworth (1995) and Ellis (1997) have proposed three types of materials evaluation: predictive or pre-use evaluation in which the future or potential performance of a textbook is examined, in-use evaluation designed to examine the currently used textbook, and retrospective or post-use of evaluation, whereby one can decide how to improve the given textbook for subsequent use.

Dudley-Evans and St John (1998) define evaluation as asking questions and acting on the responses. They further argue that evaluation "begins with determining what information to gather and ends with bringing about change in current activities or influencing future ones" (p.128). They divide evaluation into formative and summative types. They suggest that ESP practitioners should pay more attention to formative evaluation which takes place during a course and at intervals. As Dudley-Evans and St John put it, formative evaluation involves "mini-evaluations." This kind of evaluation helps to make necessary modifications to the course including materials and books. Summative evaluation takes place at the end of the course or when the course is finished. Therefore, it does not affect the course. This kind of evaluation is used to gauge the usefulness of the course and make improvement in subsequent versions of the course or materials.

Likewise, Hutchinson and Waters (1987) define evaluation as a process of matching needs to available solutions. They divide the evaluation process into 4 stages: a) defining criteria, b) subjective analysis, c) objective analysis, and d) matching. They further add that to make the best choice, different parties involved in the course have to be considered: teachers, students, and sponsors.

Robinson (1991) distinguishes between three types of materials evaluation: a) preliminary (before an ESP course begins), b) summative (takes place at the end of the course), and c) formative (conducted while the course is ongoing). She states that evaluation can be carried out by both outsiders and insiders. A further distinction made by Robinson (1991) is between process and product evaluation. The former addresses teaching and learning processes, strategies, administrative and decision-making processes, while the latter is concerned with the students' product such as examination results, essays, etc. By insiders she means teachers, students, and course designers. Robinson lists a number of tools used to carry out evaluation: questionnaires, checklists, rating scales, interviews, observation, and records.

Besides formative and summative evaluation, Richards (2001) suggests another kind of evaluation, namely illuminative. He describes this kind of evaluation as follows:

This refers to evaluation that seeks to find out how different aspects of the program work or are being implemented. It seeks to provide a deeper understanding of the processes of teaching and learning that occur in the program, without necessarily seeking to change the course in any way as a result. (p.289)

McDonough and Shaw (2003) suggest a model for textbook evaluation which involves three stages. First, external evaluation that examines the organization of materials stated by the author or the publisher including claims made on the cover page and information in introduction and table of contents. This kind of evaluation gives information about the intended audience, the proficiency level, the context of use, presentation and organization of materials, and authors' opinion about language and methodology, use of audio-visual materials, vocabulary list and index, cultural aspects, tests and exercises included in the book. Second, internal evaluation in which the following factors are examined: a) the presentation of the skills, b) the grading and sequence of the materials, c) authenticity or artificiality of the listening materials, d) authenticity or artificiality of the speaking materials, e) appropriateness of tests and materials, and f) 
appropriateness of the materials for different learning styles and claims made by the authors for self-study. The last stage is overall evaluation in which usability, generalizability, adaptability, and flexibility factors are examined.

\section{THE PRESENT STUDY}

Swan (1986, cited in Robinson, 1991) put forward eight reasons for the underdevelopment of evaluation in ESP, including the shortness or even one-off nature of ESP courses, the time consuming nature of evaluation, and the lack of any felt need for evaluation. In the Iranian context, the systematic evaluation of textbooks is not usually carried out and students' needs and opinions regarding the materials designed for them are ignored. This study seeks to investigate whether the English textbook designed for the students of social sciences is appropriate or not. In addition, the merits of undertaking the evaluation process will be discussed. It seeks therefore to answer the following research question: Is the ESP textbook designed for the students of social sciences in the Iranian context suitable for them?

\section{METHOD}

\section{A. Participants}

The participants for this study were 50 BA students of sociology (15 males and 35 females) doing an ESP course. All the participants were young people whose age varied from 19 to 21 . They studied at the University of Tehran, faculty of sociology.

\section{B. Materials}

The book to be evaluated was English for the Students of Sociology: Social Science Texts. Students were supposed to read the texts each session and translate them into Persian.

To do the evaluation, a questionnaire comprised of 20 items about the textbook was used (see Appendix A). It was based on Sheldon' (1988) model of evaluation and modified by Karimi (2006). The questionnaire examines 6 parts: practical concerns, materials in relation to course objective, subject matter, linguistic issues, skills and strategies, variety of tasks and activities, and the layout of materials. To make the items easy to understand, the researchers translated the questionnaire into Persian and it was back translated by an expert in the field. The translated version was piloted with thirty students. The Cronbach alpha reliability index turned out to be 0.76 .

\section{Procedure}

At first, the second researcher talked with the participants about the study for a few minutes and made them aware of the processes they were supposed to go through. They were informed that it was not necessary to write their names and their answers would not affect their course grade. To evaluate the effectiveness of the intended textbook, the participants were asked to give their opinion on a five-point scale: excellent, good, average, weak, and very weak.

\section{RESULTS}

The first areas under investigation were practical concerns: the first question was: to what extent is the textbook available? $70 \%$ of the participants chose excellent and $30 \%$ chose good. The second question was: to what extent can the accompanying materials be obtained in a timely manner? $13 \%$ of the participants chose good, $27 \%$ of them chose average, $31 \%$ chose weak, and $29 \%$ chose very weak alternatives. The third question was: is the text book cost effective? $10 \%$ of the participants chose excellent, $50 \%$ chose good, $25 \%$ chose average, $7 \%$ chose weak, and 8 percent chose very weak alternatives.

The second area investigated the relation between course objectives and the textbook: the first question was: to what extent do the objectives of the textbook match the objectives of the course? $8 \%$ of the participants chose excellent, $20 \%$ chose good, $23 \%$ chose average, $34 \%$ chose weak, and $15 \%$ chose very weak alternatives. The second question was: to what extent does the textbook seem to be in tune with broader educational concerns? $10 \%$ chose excellent, $25 \%$ of students chose good, $27 \%$ chose average, $25 \%$ chose weak, and $13 \%$ chose very weak alternatives. The third question was: to what extent is the textbook appropriate for the audience? $6 \%$ chose excellent, $24 \%$ chose good, $25 \%$ chose average, $35 \%$ chose weak, and $6 \%$ chose very weak alternatives.

The third area was related to the subject matter issues: the first question was: to what extent does the subject matter motivate and interest students? 3\% of the participants chose excellent, $15 \%$ chose good, $20 \%$ chose average, $39 \%$ chose weak, and the rest chose very weak alternatives. The second question was: to what extent has the ordering of by topics been arranged in a logical fashion? 24\% chose excellent, $45 \%$ chose average, $20 \%$ chose weak, and $11 \%$ chose very weak alternatives. The third question was: to what extent has the content been graded according to the needs and background knowledge of the students? $13 \%$ of the participants chose excellent, $27 \%$ chose good, $30 \%$ chose average, $15 \%$ chose weak, and the rest chose very weak alternatives.

The next part was related to language issues: the first question was: to what extent does the textbook contain the basic grammatical patterns and vocabulary? $7 \%$ of the participants chose excellent, $33 \%$ of the students chose good, $31 \%$ of the students chose average, $19 \%$ chose weak, and the rest chose very weak alternatives. The second question was: to what extent does the presentation of structure and vocabulary move from simple to difficult? $14 \%$ chose good, 
$25 \%$ chose average, $40 \%$ chose weak, and $21 \%$ chose very weak alternatives. The third question was: to what extent are the new vocabulary and structures recycled in the subsequent units for reinforcement? $10 \%$ of the participants chose excellent, $21 \%$ chose good, $23 \%$ chose average, $33 \%$ chose weak, and $13 \%$ chose very weak alternatives.

The fifth area investigated the skills and strategies involved in the questionnaire. The first question was: to what extent does the textbook teach the reading skill? $21 \%$ chose excellent, $23 \%$ chose good, $31 \%$ chose average, $13 \%$ chose weak, and the rest chose very weak alternatives. The second question was related to the strategies and skills: inference making, reading for the main idea, and guessing. The researchers decided to gather information about these skills and strategies through interview with the participants because most of them had difficulty with the concepts mentioned above. They believed that the book did not deal explicitly or even implicitly with these skills and strategies.

The next area under investigation dealt with the exercises and activities in the book. While checking the answers given by the participants, the researchers noticed that all of them had reported there is no exercise or activity in the book. It was surprising to find out about this fact. There were no exercises to reinforce what the students had learnt.

The last part of the questionnaire was related to the layout of the book. The first question was: to what extent does the book appear attractive? 19\% of participants chose good, 33\% of students chose average, 37 of them chose weak, and $11 \%$ chose very weak alternatives. The second question was: to what extent do photographs and illustrations in the book motivate you to talk about the subject? Unfortunately, there were no photographs and illustrations in the book. Table 1 summarizes the findings of the study.

TABLE 1.

PARTICIPANTS' OPINION ABOUT THE TEXTBOOK

\begin{tabular}{|c|c|c|c|c|c|}
\hline Degree $\quad$ Criteria & Very weak & Weak & Average & Good & Excellent \\
\hline $\begin{array}{l}\text { To what extent is the text book } \\
\text { available? }\end{array}$ & - & - & - & $30 \%$ & $70 \%$ \\
\hline $\begin{array}{l}\text { To what extent can the } \\
\text { accompanying materials be } \\
\text { obtained in a timely manner? }\end{array}$ & $29 \%$ & $31 \%$ & $27 \%$ & $13 \%$ & - \\
\hline Is the text book cost effective? & $8 \%$ & $7 \%$ & $25 \%$ & $50 \%$ & $10 \%$ \\
\hline $\begin{array}{l}\text { To what extent do the objectives of } \\
\text { the textbook match the objectives of } \\
\text { the course? }\end{array}$ & $15 \%$ & $34 \%$ & $23 \%$ & $20 \%$ & $8 \%$ \\
\hline $\begin{array}{l}\text { To what extent does the textbook } \\
\text { seem to be in tune with broader } \\
\text { educational concerns? }\end{array}$ & $13 \%$ & $25 \%$ & $27 \%$ & $25 \%$ & $10 \%$ \\
\hline $\begin{array}{l}\text { To what extent is the textbook } \\
\text { appropriate for the audience? }\end{array}$ & $6 \%$ & $35 \%$ & $25 \%$ & $24 \%$ & $6 \%$ \\
\hline $\begin{array}{l}\text { To what extent does the subject } \\
\text { matter motivate and interest } \\
\text { students? }\end{array}$ & $23 \%$ & $39 \%$ & $20 \%$ & $15 \%$ & $3 \%$ \\
\hline $\begin{array}{l}\text { To what extent has the ordering of } \\
\text { topics been arranged in a logical } \\
\text { fashion? }\end{array}$ & $11 \%$ & $20 \%$ & $45 \%$ & - & $24 \%$ \\
\hline $\begin{array}{l}\text { To what extent has the content been } \\
\text { graded according to the needs and } \\
\text { background knowledge of the } \\
\text { students? }\end{array}$ & $5 \%$ & $15 \%$ & $30 \%$ & $27 \%$ & $13 \%$ \\
\hline $\begin{array}{l}\text { To what extent does the textbook } \\
\text { contain the basic grammatical } \\
\text { patterns and vocabulary? }\end{array}$ & $10 \%$ & $19 \%$ & $31 \%$ & $33 \%$ & $7 \%$ \\
\hline $\begin{array}{l}\text { To what extent does the } \\
\text { presentation of structures and } \\
\text { vocabulary move from simple to } \\
\text { difficult? }\end{array}$ & $21 \%$ & $40 \%$ & $25 \%$ & $14 \%$ & - \\
\hline $\begin{array}{l}\text { To what extent are the new } \\
\text { vocabulary and structures recycled } \\
\text { in the subsequent units for } \\
\text { reinforcement }\end{array}$ & $13 \%$ & $33 \%$ & $23 \%$ & $21 \%$ & $10 \%$ \\
\hline $\begin{array}{l}\text { To what extent does the textbook } \\
\text { teach the reading skill? }\end{array}$ & $11 \%$ & $13 \%$ & $31 \%$ & $23 \%$ & $21 \%$ \\
\hline $\begin{array}{l}\text { To what extent does the book } \\
\text { appear attractive? }\end{array}$ & $11 \%$ & $37 \%$ & $33 \%$ & $19 \%$ & - \\
\hline
\end{tabular}

\section{DISCUSSION AND CONCLUSION}

As mentioned earlier, the major areas under investigation in the questionnaire were practical concerns, materials in relation to course objectives, exercises and activities, skills and strategies, language issues, and subject matter.

At first it should be noted that every textbook or teaching material has its merits. No teaching material is perfect. As it was observed in the previous section, the book in question was relatively suitable regarding some areas under 
examination such as cost-effectiveness, availability, and presentation of basic grammatical patterns and vocabulary. The main goal of this research was to make some practical suggestions to improve the quality of this and other similar ESP textbooks.

Regarding the first area, it was revealed that the main problem was with the supplementary materials. These materials can help students improve their English and learn the textbook contents better. With respect to the second area, it should be mentioned that there was no explicit statement of the purpose in the book. Moreover, students were not aware of the major goals of the course. Regarding the subject matter issues, it is obvious that the book is not motivating. The level of students was not taken into consideration and the topics were not appealing. The next area was related to language issues. With respect to the basic grammatical structures and vocabulary, the participants were pleased with the book. However, this was not the case for two other questions. There was no logical order from simple to difficult and no recycling of the structures and vocabulary. With respect to skills and strategies, as mentioned previously, the participants had a negative attitude toward the textbook. The goal of ESP is to teach learners how to read efficiently by practicing useful skills and strategies such as inference making, guessing the meaning of unknown words from the context, etc.

The layout of the book plays an important role in catching the learners' attention and increasing their motivation. Unfortunately, the book under investigation did not have any photographs or illustrations. This is definitely a source of boredom for the learners.

To provide a suitable textbook for learners, different issues should be taken into consideration like the background knowledge and English level of the learners. However, as seen in the previous section, most of the participants believed that the book was not in harmony with their English proficiency. Simple structures and vocabulary should be introduced earlier, so the students will not be overwhelmed with a huge number of new structures. This, however, was not observed in the present textbook.

Exercises and activities have the role of consolidating what has been learned. It is difficult to imagine a book with no exercises or activities, which should encourage learners to think about what the texts really mean and use their cognitive abilities to solve the given problems. Pedagogical task are good examples of such activities, which were absent in the present textbook.

The main reason for unsuitability of many ESP textbooks is the lack of needs analysis. In many cases, conducting needs analysis is ignored before the course begins, so there is not enough information about the students for which the textbook is provided. While writing the materials, the textbook writers do not have the intended audience in their mind, which forces them to follow predetermined guidelines for all courses.

ESP textbooks should arouse the interest of the students and be motivating. One of the techniques which can be used to achieve this goal is to use pictures, illustrations, tasks, and authentic materials. The materials should include discussion questions, prediction activities, skimming and scanning exercises, and tasks which stimulate critical analysis and evaluation of what they have read. Textbooks should provide the learners with activities which ask them to complete tables, flowcharts, and diagrams. Theses activities draw the learners' attention to the most salient ideas in the text. The content of the books should be related to the previous learning experience and background knowledge of the learners. This is what scholars call meaningful learning. A suitable textbook should cover necessary grammatical structures and be adequate in terms of quantity and range of vocabulary. Besides, it should include pronunciation practice as well as issues of style and appropriacy in correct use of English.

\section{APPENDIX A QUESTIONNAIRE}

\section{Dear participants}

The following questionnaire is intended for a research on textbook evaluation. Please read the questions carefully and express your idea by selecting one of the options.

1. To what extent is the book available?
a. excellent
b. good
c. average
d. weak
e. very weak

2. To what extent can the accompanying materials be obtained in a timely manner?
a. excellent
b. good
c. average
d. weak
e. very weak

3. Is the text book cost-effective?
a. excellent
b. good
c. average
d. weak
e. very weak

4. To what extent do the objectives of the textbook match the objectives of the course?
a. excellent
b. good
c. average
d. weak
e. very weak

5. To what extent does the textbook seem to be in tune with broader educational concern?
a. excellent
b. good
c. average
d. weak
e. very weak

6. To what extent is the text book appropriate for he audience?
a. excellent
b. good
c. average
d. weak
e. very weak

7. To what extent does the textbook contain basic grammatical patterns and vocabulary?
a. excellent
b. good
c. average
d. weak
e. very weak

8. To what extent does the presence of structures and vocabularies move gradually from simple to more complex? 
$\begin{array}{llll}\text { a. excellent } & \text { b. good } \quad \text { c. average d. weak e. very weak }\end{array}$

9. To what extent are new vocabularies and structures recycled in subsequent units for reinforcement?
a. excellent
b. good
c. average
d. weak
e. very weak

10. To what extent does the subject matter motivate and interest you?
a. excellent
b. good
c. average
d. weak
e. very weak

11. To what extent has the ordering of the material by topics been arranged in a logical fashion?
a. excellent
b. good
c. average
d. weak
e. very weak

12. To what extent has the content been graded according to the need and background knowledge of the students?
a. excellent
b. good
c. average
d. weak
e. very weak

13. To what extent does the textbook teach the reading skill?
a. excellent
b. good
c. average
d. weak
e. very weak

14. To what extent does the textbook teach reading strategies?
a. excellent
b. good
c. average
d. weak
e. very weak

15. To what extent does the textbook teach the speaking skill?
a. excellent
b. good
c. average
d. weak
e. very weak

16. Are the exercises and activities varied enough to challenge the students?
a. excellent
b. good
c. average
d. weak
e. very weak

17. To what extent does the textbook appear attractive?
a. excellent
b. good
c. average
d. weak
e. very weak

18. To what extent do photographs and illustrations in the book motivate you to talk about the subject?
a. excellent
b. good
c. average
d. weak
e. very weak

19. To what extent are the materials related to your major?
a. excellent
b. good
c. average
d. weak
e. very weak

20. To what extent has the content been graded according to the proficiency level of the students?
a. excellent
b. good
c. average
d. weak
e. very weak

\section{REFERENCES}

[1] Allwright, R. (1981). What do we want teaching materials for? ELT Journal, 36, 5-18.

[2] Brown, J. (1995). The elements of language curriculum: A systematic approach to program development. New York: Heinle \& Heinle Publishers.

[3] Cunningsworth, A. (1995). Choosing your coursebook. Oxford: Heinemann.

[4] Dudley-Evans, T., \& St. John, M. J. (1998). Developments in English for specific purposes: A multi-disciplinary approach. Cambridge: Cambridge University Press.

[5] Ellis, R. (1997). The empirical evaluation of language teaching materials. ELT Journal, 51, 36-42.

[6] Hutchinson, T., \& Torres, E. (1994). The textbook as agent of change. ELT Journal, 48, 315-328.

[7] Hutchinson, T., \& Waters, A. (1987). English for specific purposes: A learning-centered approach. Cambridge: Cambridge University Press.

[8] Karimi, S. (2006). ESP textbook evaluation: English for the students of computer. Unpublished master's thesis, Allameh Tabataba'i University, Tehran, Iran.

[9] McDonough, J., \& Shaw, C. (2003). Materials and methods in ELT. Oxford: Blackwell.

[10] Nunan, D. (1991). Language teaching methodology: A textbook for teachers. London: Prentice Hall.

[11] O’Neill, R. (1982). Why use textbooks? ELT Journal, 36, 104-111.

[12] Riazi, A. M. (2003). What textbook evaluation schemes tell us? A study of the textbook evaluation schemes of three decades. In W. A. Renandya. (Ed.), Methodology and materials design in language teaching (pp. 52-68). Singapore: SEAMEO Regional Center.

[13] Richards, J.C. (2001). Curriculum development in language teaching. Cambridge: Cambridge University Press.

[14] Robinson, P.C. (1991). ESP today: A practitioner's guide. Hemel Hempstead: Prentice Hall.

[15] Sheldon, L. (1988). Evaluating ELT textbooks and materials. ELT Journal, 37, 237-246.

[16] Stern, H.H. (1992). Issues and options in language teaching. Oxford: Oxford University Press.

[17] Swales, J. (1980). The educational environment and its relevance to ESP program design: ELT Documents special projects in materials design. London: ETIC Publications, the British Council.

Sasan Baleghizadeh is an Assistant Professor of TEFL at Shahid Beheshti University, G.C. of Iran, where he teaches applied linguistics, syllabus design, and materials development. He is the author of a number of simplified readers such as Tales from Rumi and Tales from Men of Wisdom all published by the Iran Language Institute. His recent publications have appeared in, ELT Journal, The Teacher Trainer, and Theory and Practice in Language Studies.

Amir Hossein Rahimi holds an MA degree in TEFL from Allameh Tabataba'i University of Iran. His research interest lies in investigation of language learning strategies employed in EFL listening comprehension. He has recently published in Theory and Practice in Language Studies. 